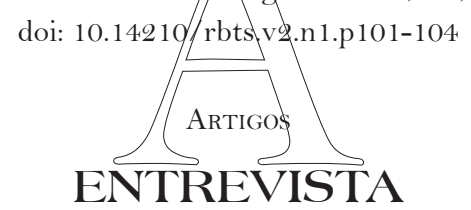

\title{
Tecnologia Assistiva: surge uma nova realidade para as pessoas com deficiência física
}

Revista Brasileira de Tecnologias Sociais
*Professores do Mestrado em Gestão de Políticas Públicas da UNIVALI

\author{
Por Carlos Golembiewski e Fabíola Hermes Chesani*
}

A Tecnologia Assistiva é uma área do conhecimento, de característica interdisciplinar, que engloba produtos, recursos, metodologias, estratégias, práticas e serviços. No Brasil, a Tecnologia Assistiva é uma área de conhecimento relativamente nova e as pesquisas enfatizam a necessidade do envolvimento de profissionais especializados em diferentes áreas do conhecimento para o trabalho com pessoas com deficiência. O Programa de Mestrado em Saúde e Gestão do Trabalho e o Curso de Fisioterapia da Univali desenvolvem pesquisas com mestrandos e graduandos de diferentes áreas da saúde sobre o tema em questão, fruto de uma parceria com a Universidade de Brighton. Esta parceria aprovou pelo edital Newton Mobility Grant Scheme 2015 Round 1 o trabalho intitulado "Breaking down barriers and improving quality of life for wheelchair users”. Aproveitando a oportunidade desta parceria, a professora da Universidade de Brighton, Anne Mundy, com importante experiência no processo de Tecnologia Assistiva, esteve em junho deste ano na Univali para ministrar a palestra "Tecnologia Assistiva e mobilidade de pessoas com deficiência física”. Após o evento, a professora conversou com a Revista Brasileira de Tecnologias Sociais. 


\section{O que é tecnologia assistiva?}

Tecnologia assistiva envolve uma série de equipamentos que ajudam as pessoas que não têm os movimentos normais a serem capazes de se mover e de viver uma vida normal.

\section{Como estão Brasil e Inglaterra com relação a este processo?}

Existem poucos exemplos de tecnologia assistiva no Brasil, e parte da razão da minha visita nesta última semana foi trazer diferentes peças de equipamentos para demonstrar o que está disponível para pessoas que sofreram nova deficiência recente ou que tiveram um AVC, ou que não estão aptas a moverem seus membros; por isso trouxemos uma cadeira de rodas especializada, que as pessoas podem usar apenas com um braço e uma perna para a trava e para a direção, bem como vários dispositivos para alimentação que permitem que as pessoas com atividades musculares fracas nos braços ou com problemas neurológicos possam ser capazes de se alimentar de forma independente. E também compramos uma variedade de tipoias que permitem que as pessoas possam escovar o cabelo, atender o telefone, serem capazes de fazer "balé", pintar ou até mesmo tocar piano, todos esses equipamentos permitem que sejam independentes e que aproveitem a vida totalmente.

\section{Quais países estão conduzindo este processo de tecnologia assistiva?}

Há vários países líderes no campo da tecnologia assistiva, porém com a cadeira de rodas para um só braço, apenas nós no Reino Unido.

\section{Como é a parceria de pesquisa entre a Univali e a Brighton University?}

A doutora Chesani entrou em contato comigo depois de ter lido alguns dos meus trabalhos e perguntou se poderíamos desenvolver uma proposta para trabalhar em conjunto, foi o que fizemos e apresentamos esse pedido à British Academy para um prêmio chamado The Newton Mobility Award que permite a transferência de professores universitários entre o Brasil e a Inglaterra, e tivemos êxito. Este prêmio permitiu que a professora Chesani me visitasse no Reino Unido por duas semanas em outubro passado, para que eu faça essa visita de volta agora e para que a professora venha me visitar novamente em julho.

\section{Que tipos de testes estão sendo feitos com esta cadeira de rodas inovadora?}

Assumimos a organização de projetos de pesquisa de modo a avaliar eficiência física e eficiência ergonômica. Também analisamos e comparamos a cadeira de rodas com outras cadeiras da concorrência em situações aplicadas, assim usamos a cadeira em lugares da casa para comparar as diferenças nas habilidades realizadas diariamente, como fazer a cama, colocar a mesa, em relação a o que os usuários sentiram com o uso da cadeira de rodas em casa e como isso mudou suas vidas. Também observamos a força da mão que impulsiona a cadeira de rodas e a força na base, com a perspectiva de prevenir uma fonte precária. E a parte final do trabalho foi medir as atividades do ombro e as atividades dos músculos para descobrir qual cadeira de rodas era mais eficiente, e foi a nossa.

6. Como é o sistema de saúde pública inglês? É o mais eficiente do mundo?

O sistema inglês é um sistema "supervisionado", o programa nacional oferece ajuda gratuita para todos, mas existe um sistema privado adicional de assistência médica pelo qual as pessoas podem pagar se quiserem também. No entanto, a saúde pública fornece tecnologia assistiva, então os pacientes que necessitam de equipamentos como estes são avaliados por fisioterapeuta, 
terapeuta ocupacional e técnicos de engenharia, para verificar se o equipamento está apropriado, e em seguida, um organismo financiador fornece o financiamento para que os pacientes tenham esta peça do equipamento.

\section{Você é a favor da consulta médica paga no sistema de saúde pública?}

Como país, damos a opção para que pessoas que desejem pagar por cuidados adicionais possam fazer isso.

8. Na sua opinião, o serviço de saúde deve ser público ou pode ter uma participação privada, como no Brasil e em outros países?

Nós temos os dois. A assistência médica está sob muita pressão e lutando muito por causa das mudanças políticas no Reino Unido, e há uma reorganização muito grande acontecendo, o que tem também muito impacto internamente no volume de recursos disponíveis para dar apoio à assistência médica neste momento.

9. No Brasil, temos muita corrupção em nosso sistema nacional de saúde, o que você pensa sobre isso, pessoas que não cumprem seu horário de trabalho, como podemos mudar isso?

Eu acho que em grandes organizações que oferecem serviços, tais como assistência médica, onde há muitas pessoas empregadas, sempre haverá um certo nível de corrupção. No entanto, é importante que ele seja administrado e, na realidade, a assistência médica forneça assistência médica para seus usuários.

10. Você acha que o serviço de saúde pública no Reino Unido, que funciona, depende da educação do país? Porque no Brasil, a educação não é tão boa, então o serviço de saúde também não funciona.

Foram feitos muitos estudos que analisaram a classe social e existem relações e correlações relatadas sobre a falta de renda, falta de educação, saúde precária e, certamente, esses são fatores de risco para doenças cardíacas. Se esse é o caso no mundo em que eu trabalho, de novas deficiências, não acredito que seja, embora existam relações entre saúde precária e AVCs, assim saúde pública ruim, tabagismo, alcoolismo, stress excessivo que são pré-fatores para o desenvolvimento de um ataque cardíaco ou um AVC.

\section{Você poderia falar um pouco sobre a cadeira de rodas neater winnie?}

A cadeira de rodas neater winnie, que é uma cadeira de rodas que eu desenvolvi com uma empresa de engenharia com consultores clínicos e pacientes, surgiu porque estava muito claro do ponto de vista da fisioterapeuta e da terapeuta ocupacional, que a cadeiras de rodas disponíveis não estavam atendendo às necessidades dos usuários. Elas eram difíceis de dirigir, pesadas e seus usuários não conseguiam usá-las, por isso, ao longo dos últimos 10 anos, estamos trabalhando com usuários e engenheiros para desenvolver um modelo que atenda às necessidades deste grupo de pessoas, e é isso que nós temos feito.

\section{Quanto tempo até que essas inovações estejam disponíveis para as pessoas?}

Já estão disponíveis. A cadeira de rodas é fabricada, por isso somos capazes de fornecêla por meio de nossa prestação de serviços de cadeira de rodas para hospitais e terapeutas que prescrevem o uso da mesma. Então elas podem ser utilizá-las em suas próprias casas, em lar para idosos e também na área externa, em determinados ambientes, como shoppings, parques, calçadão. 


\section{Por quanto tempo você tem estudado cadeira de rodas?}

O desenvolvimento da cadeira de rodas levou 10 anos, nós trocamos ideias por 2 anos, e fomos financiados por diferentes organizações e recebemos doações que nos deram dinheiro suficiente para desenvolver o primeiro protocolo, com o primeiro modelo. Estávamos então em condições de fazer inscrição no sistema nacional de saúde, que financiou o desenvolvimento do protocolo que fizemos, e em seguida, voltamos ao sistema nacional de saúde que nos deu ajudou mais uma vez com recursos analisa se a cadeira era adequada para o grupo de pessoas que a estava usando, mas o projeto inteiro levou 10 anos.

\section{Depois de todos esses anos, você ainda é apaixonada pelo Projeto?}

Sim, para mim é muito importante que as pessoas tenham acesso ao equipamento certo, e eu fico muito frustrada com barreiras financeiras, burocráticas e políticas que impedem que as pessoas se beneficiem de equipamentos que elas precisam. 